\title{
Seroprevalence of Hepatitis B and C Infections in Mokolo District Hospital, Northern Cameroon: The Value of a Screening Campaign
}

\author{
Abdoul Rahamane Njigou ${ }^{1}$, Joël Noutakdie Tochie ${ }^{2 *}$, Celestin Danwang ${ }^{3}$, Frank-Leonel Tianyi ${ }^{4}$, Ronni \\ Tankeu $^{5}$, Veronica Aletum ${ }^{6}$, Mazou N. Temgoua ${ }^{5}$

\begin{abstract}
'Pharmacy Departement, Mokolo District Hospital, Far-North Region, Cameroon
${ }^{2}$ Faculty of Medicine and Biomedical Sciences, University of Yaounde I, Yaounde, Cameroon

${ }^{3}$ Departement of Surgery and Sub-Specialties, Faculty of Medicine and Biomedical Sciences, University of Yaounde I, Yaounde, Cameroon

${ }^{4}$ Mayo Darle Sub-Divisional Hospital, Mayo Darle, Cameroon

${ }^{5}$ Departement of Internal Medicine and Sub-Specialities, Faculty of Medicine and Biomedical Sciences, University of Yaounde I, Yaounde, Cameroon

${ }^{6}$ Departement of Physiology, Biochemistry and Pharmacology, Faculty of Medicine and Biomedical Sciences, University of Yaounde I, Yaounde, Cameroon
\end{abstract}

*Corresponding Author: Joël Nouktadie Tochie, M.D., Faculty of Medicine and Biomedical Sciences, University of Yaoundé 1, Yaoundé, Cameroon. Tel: +237-676558825, Email: joeltochie@gmail.com

Received January 17, 2018; Accepted March 6, 2018; Online Published April 21, 2018

\begin{abstract}
Background: Infections due to the hepatitis B (HBV) and hepatitis C (HCV) viruses constitute a global public health problem. Although screening of these infections remains a pivotal tool for timely detection and management of carriers, this preventive measure has been neglected in Africa.

Objective: The current study determined the prevalence of hepatitis B surface antigen (HBsAg) and anti-HCV as well as their risk factors through a screening campaign organized in a rural setting in northern Cameroon.

Methods: A cross-sectional analytical study was conducted during a screening campaign for viral hepatitis organized at the Mokolo District Hospital, Cameroon, from January 19, 2017 to February 27, 2017. Sociodemographic data from all consenting participants was collected and each participant was examined for signs of chronic liver disease. Participants were then screened for HBsAg and anti-HCV using a rapid diagnostic test $\left(\mathrm{ACON}^{\circledR}\right)$.

Results: Of the 364 participants enrolled, 28.6\% tested positive for HBsAg and 2.2\% for anti-HCV. All HBsAg-positive and anti-HCV-positive individuals were asymptomatic and unaware of their infection status prior to testing. None of the sociodemographic factors assessed was associated with a positive HbsAg status.

Conclusion: HBV and HCV infections are endemic in this rural health district. Participants who tested positive were apparently healthy and completely unaware of their infection status. Transmission of the hepatitis virus may be a public health concern in this district. It is recommended that community health education activities on preventive measures for HBV and HCV infections, regular screening for disease surveillance, and close follow-up of disease progression in these asymptomatic individuals be conducted.

Keywords: Hepatitis B Virus, Hepatitis C Virus, Rural, Cameroon, Screening, Seroprevalence
\end{abstract}

\section{Background}

Viral hepatitis is a major global public health problem, predominantly affecting low- and middle-income countries (LMIC) in the African and western Pacific regions. ${ }^{1}$ Hepatitis $B$ virus (HBV) and hepatitis $\mathrm{C}$ virus (HCV) infections account for a significant proportion of viral hepatitis infections. ${ }^{1}$ Worldwide, 2 billion people are infected with hepatitis B, and there are 257 million and
71 million cases of chronic HBV and HCV infections, respectively. ${ }^{2}$ In all, about 1.4 million people died from viral hepatitis-related causes (cirrhosis and hepatocellular cancer) in 2015, with HBV and HCV responsible for $96 \%$ of these deaths. ${ }^{2}$ This number is greater than the number of deaths caused by HIV/AIDS and compares to the annual number of deaths due to tuberculosis. ${ }^{2}$ The median seroprevalence of hepatitis B surface antigen ( $\mathrm{HBsAg}$ ) is

Copyright $\odot 2018$ The Author(s). This is an open-access article distributed under the terms of the Creative Commons Attribution License (http:// creativecommons.org/licenses/by/4.0), which permits unrestricted use, distribution, and reproduction in any medium, provided the original work is properly cited. 
estimated to be $6.9 \%$ in Nigeria, $8 \%$ in Ivory Coast, $12 \%$ in Ghana, $14.2 \%$ in Zimbabwe, and $15.5 \%$ in Benin. ${ }^{3}$

Previously cited risk factors for these infections in Africa include being born of an HBV-positive mother, ${ }^{4}$ having a history of scarification, ${ }^{5}$ prior contact with a jaundiced or HBV-infected individual, ${ }^{6}$ blood transfusion, ${ }^{7}$ history of sexually transmitted diseases, ${ }^{8,9}$ and multiple sexual partners. ${ }^{8,9}$ Likewise, recent reports ${ }^{10-12}$ portray that a younger African population seems to be more affected by these viral infections, suggesting high rates of feto-maternal transmission. Also, due to shared routes of transmission, the advent of the HIV pandemic has increased the health burden associated with these infections in Africa through the earlier onset and rapid progression of complications. ${ }^{10}$ The risk of acquiring HBV or HCV infections is 1.4- to 1.6fold higher among HIV-positive individuals. ${ }^{10}$

In response to this situation, the World Health Organization (WHO) adopted the Global Health Sector Strategy on viral hepatitis, 2016-2021, which calls for the eradication of the public health threat of viral hepatitis by 2030 and the reduction of new infections and mortality by $90 \%$ and $65 \%$, respectively. ${ }^{2}$ However, limited access to affordable testing and the largely asymptomatic nature of these infections ${ }^{11,12}$ prevent early detection and appropriate management, with a resultant increase in morbidity and mortality, particularly in LMICs. ${ }^{13,14}$ Screening campaigns present a unique opportunity to test healthy individuals for HBV or HCV infections with the aim of identifying healthy carriers, reducing horizontal and vertical transmission, preventing progression to chronic liver disease or hepatocellular carcinoma (HCC), and reducing mortality. ${ }^{2,15}$ Hence, the WHO recommends routine testing of all adults living in areas with known seroprevalences of $\geq 2 \%$ for HBsAg and $\geq 5 \%$ for anti-HCV antibodies (anti$\mathrm{HCV}) .{ }^{16}$

Cameroon is a highly endemic country with prevalence rates of $11.2 \%{ }^{17}$ and $6.5 \%{ }^{18}$ for $\mathrm{HBV}$ and $\mathrm{HCV}$ infections, respectively. The hepatitis $B$ vaccine was introduced in 2005 as a routine vaccine under the expanded program of immunization (EPI) in Cameroon ${ }^{3}$ in line with the WHO recommendations of $1991 .^{19}$ By 2015, a coverage rate of $83 \%$ was achieved for hepatitis $\mathrm{B}$ vaccination among Cameroonian children, ${ }^{3}$ and some studies reported a dramatic reduction in the prevalence of HBsAg and anti$\mathrm{HBc}$ among offspring born after 2005. ${ }^{20}$ Though prevalence studies are critical in guiding the appropriate allocation of resources for the elimination of $\mathrm{HBV}$ and $\mathrm{HCV},{ }^{21}$ there is little data on interventions like screening campaigns to estimate HBV and HCV seroprevalence in rural settings in Cameroon. Furthermore, the recent systematic review conducted on the seroprevalence of $\mathrm{HCV}$ infection in Cameroon by Bigna et al had no representative data from northern Cameroon. ${ }^{18}$

In addition to investigating seroprevalence, risk factors for HBV and HCV infections need to be identified in each setting so as to allow for the implementation of appropriate preventive interventions.

\section{Objective}

This study sought to determine the seroprevalence and risk factors for $\mathrm{HBV}$ and $\mathrm{HCV}$ infections in a rural health district in northern Cameroon.

\section{Methods}

This cross-sectional, analytical study was carried out in the Mokolo District Hospital of Cameroon from January 19, 2017 to February 27, 2017. Mokolo is the headquarter of the Mayo-Tsanaga division in the far-north region of Cameroon and is home to 289776 inhabitants, most of whom are Muslims. Mokolo is a rural area covering a surface area of $1000 \mathrm{~km}^{2}$ and situated in proximity to the Cameroon-Nigeria borders. The main activities of the native population are cattle rearing and farming. The health district of Mokolo is made up of six private and 12 government integrated health centers. The Mokolo District Hospital is situated in the center of the district and serves as the main referral center for the entire health district. ${ }^{22}$ All consenting inhabitants of Mokolo aged above 17 years were consecutively enrolled in the current study during a screening campaign of $\mathrm{HBV}$ and $\mathrm{HCV}$ infections at the Mokolo District Hospital.

A structured questionnaire was used to collect sociodemographic data on age, gender, level of education, profession, and marital status. All participants were then briefly physically examined for signs of liver disease: jaundice, palmar erythema, finger clubbing, petechiae or purpura, leukonychia, easy bruising, Dupuytren's contracture, right upper quadrant tenderness, hepatomegaly, gynaecomastia, and atrophied testes. Samples of three milliliters of venous blood were collected into an ethylenediaminetetra-acetic acid (EDTA) tube through a venipuncture of the anterior cubital vein of each participant. Blood samples were centrifuged for five minutes, after which plasma was collected and tested for the presence of HBsAg and anti-HCV using rapid diagnostic test strips $\left(\mathrm{ACON}^{\circledR}\right)$. These test strips use an immunochromatographic method derived from the enzyme-linked immunosorbent assay (ELISA) technique for the detection of HBsAg and anti-HCV. To this end, a pipette was used to deposit two drops of plasma onto the corresponding receiving section of the strip. A minimum time lapse of 5 minutes was observed before reading the results.

Testing procedures and result interpretation followed the manufacturer's instructions. Test results (HBsAg and anti$\mathrm{HCV}$ ) were considered positive when 2 bands appeared: one in the control zone and another in the test zone. The results were negative if only one band appeared in the control zone and none in the test zone. The results were invalid when no band was seen in the control region. For invalid results, the test was repeated using a new strip. Cases which tested positive for HBsAg or anti-HCV further underwent a confirmatory enzyme immunoassay test.

Data was analyzed using Epi Info version 3.5.4. The seroprevalence of $\mathrm{HBV}$ was calculated as the ratio between 
HBsAg positive samples to the total samples collected. Likewise, the seroprevalence of HCV was determined as the ratio of anti-HCV positive samples to the total samples collected. Means, medians, and interquartile ranges (IQR) were used to summarize continuous variables, while frequencies and proportions were calculated for categorical variables. The chi-square test was used to compare categorical variables where applicable. Statistical significance was set at a $P$ value less than $5 \%$.

\section{Results}

A total of 364 participants were enrolled in this study, of whom $199(54.7 \%)$ were females. The median age was 38 years (interquartile: $30-75$ ), and half of the study population was aged between 19-39 years. One third had a secondary level of education, one third were housewives, and $82.7 \%$ were married (Table 1 ).

Of the 364 participants screened, 104 (28.6\%) and 8 (2.2\%) tested positive for $\mathrm{HBsAg}$ and anti-HCV, respectively. All patients who tested positive were asymptomatic. Due to the small number of anti-HCV-positive participants, risk factors were assessed only for HBsAg-positive participants. None of the socio-demographic variables assessed was associated with HBsAg positivity (Table 2).

\section{Discussion}

This study aimed to determine the seroprevalence and risk factors of HBV and HCV through a screening campaign organized in Mokolo District Hospital. Prevalence rates of 28.6\% and 2.2\% for HBV and HCV infections, respectively, were found. None of the factors assessed was associated

Table 1. Socio-demographic Characteristics of Participants

\begin{tabular}{|c|c|c|}
\hline Variables & Number $(n=364)$ & Percent \\
\hline \multicolumn{3}{|l|}{ Age groups (y) } \\
\hline$<19$ & 12 & 3.3 \\
\hline $19-39$ & 182 & 50 \\
\hline $40-59$ & 136 & 37.4 \\
\hline 60 & 34 & 9.3 \\
\hline \multicolumn{3}{|l|}{ Gender } \\
\hline Female & 199 & 54.7 \\
\hline Male & 165 & 45.3 \\
\hline \multicolumn{3}{|c|}{ Level of education } \\
\hline Informal & 103 & 28.3 \\
\hline Primary & 73 & 20.1 \\
\hline Secondary & 124 & 34.1 \\
\hline Higher & 64 & 17.6 \\
\hline \multicolumn{3}{|l|}{ Marital status } \\
\hline Married & 301 & 82.7 \\
\hline Unmarried & 63 & 17.3 \\
\hline \multicolumn{3}{|l|}{ Occupation } \\
\hline Employed & 191 & 52.4 \\
\hline Housewife & 125 & 34.6 \\
\hline Pupil/student & 33 & 9.3 \\
\hline Unemployed & 15 & 4.1 \\
\hline
\end{tabular}

with HBsAg positivity.

This prevalence rate ranks the Mokolo health district as a zone of high $(\geq 8 \%)$ and intermediate $(2 \%-4 \%)$ endemicity for $\mathrm{HBV}$ and $\mathrm{HCV}$, respectively. ${ }^{23}$ This result can probably be explained by the fact that the majority of childbirths in this region occur at home, and thus the provision of perinatal preventive measures for mother-to-child transmission of $\mathrm{HBV}$ is hindered. ${ }^{24}$ Also considering the fact that all participants who tested positive were unaware of their current infection status, the high prevalence rates in this study are particularly worrisome, as they suggest possible uncontrolled and unintended transmission from carriers to uninfected individuals within this community through multiple means of transmission. The seroprevalence of HBsAg rates found in this study concur with those of Noah et $\mathrm{al},{ }^{25}$ who observed a rate of $22.8 \%$ for HBsAg in the farnorth region of Cameroon. Indeed, the seroprevalence of $\mathrm{HBV}$ is higher in the far-north region of Cameroon than in other regions of the country; other studies have reported prevalence rates of $11.8 \%$ for HBsAg and $0.6 \%$ for anti$\mathrm{HCV}$ in the east, ${ }^{26} 4.1 \%$ for HBsAg and $0.4 \%$ for anti-HCV in the west, ${ }^{27} 10.1 \%$ for HBsAg and $4.8 \%$ for anti-HCV in the Littoral Region, ${ }^{28} 4.39 \%-12.14 \%$ for $\mathrm{HBsAg}^{29,30}$ and $1.44 \%$ for anti- $\mathrm{HCV}^{30}$ in the center region, and $9.7 \%$ for HBsAg in the southwest region. ${ }^{31}$

The current study did not identify factors significantly associated with HBsAg positivity in contrast with other studies which reported at least one risk factor. ${ }^{6-8}$ The heterogeneity between communities' determinants of hepatitis infection could account for these disparities. Also, the inability to precisely recall high-risk events which might have predisposed one to HBsAg infection limited the identification of potential risk factors. Hence, this study failed to identify any risk factors for a positive HbsAg test result. Furthermore, the dominant social context (being a Muslim community) precluded the disclosure of information related to sexual behaviors, such as age at first intercourse,${ }^{8}$ history of sexually transmitted diseases,${ }^{8,9}$ and multiple sexual partners. ${ }^{8,9}$

The adoption of a more robust vaccination system can reduce the burden imposed by $\mathrm{HBC}$ and $\mathrm{HCV}$ infections in this rural health district. The anti-HBV vaccine is highly immunogenic and well tolerated in all age groups. ${ }^{32}$ Routine administration of all three doses of the pentavalent vaccine (Zilbrix ${ }^{\mathrm{TM}}$, a DTPw-HBV combination vaccine) to infants at 6,10 , and 14 weeks of age should be emphasized. The same protocol should be used in unvaccinated adults. For almost two decades, the Global Alliance for Vaccines and Immunization in collaboration with the Cameronian Ministry of Public Health have included HBV vaccination in the EPI, rendering the vaccine free for children less than 11 months of age and achieving a coverage rate of $83 \%$ in the year $2015 .{ }^{3}$ Many efforts are needed to achieve full coverage, more so in rural areas where high rates of illiteracy translate to low rates of awareness and an increased risk of viral transmission of hepatitis. ${ }^{18}$ At the time of the current study, there was a shortage of supply of 
Table 2. Factors Associated With HBsAg Positivity in Mokolo District Hospital

\begin{tabular}{|c|c|c|c|c|c|}
\hline Variable & $\begin{array}{c}\text { HBsAg Positive } \\
(n=104)\end{array}$ & $\begin{array}{c}\text { HBsAg Negative } \\
(\mathbf{n = 2 6 0 )}\end{array}$ & Odds ratio & $95 \% \mathrm{Cl}$ & $P$ Value \\
\hline \multicolumn{6}{|l|}{ Gender } \\
\hline Female & $50(48 \%)$ & $115(44 \%)$ & 0.86 & $0.54-1.35$ & 0.505 \\
\hline Male & $54(52 \%)$ & $145(56 \%)$ & & & \\
\hline \multicolumn{6}{|l|}{ Marital status } \\
\hline Married & $86(83 \%)$ & $215(83 \%)$ & 1.0 & $0.55-1.82$ & 0.999 \\
\hline Unmarried & $18(17 \%)$ & $45(17 \%)$ & & & \\
\hline \multicolumn{6}{|c|}{ Level of education } \\
\hline$\leq$ Primary & $54(52 \%)$ & $122(47 \%)$ & 1.22 & $0.78-1.93$ & 0.389 \\
\hline$>$ Primary & $50(48 \%)$ & $138(53 \%)$ & & & \\
\hline \multicolumn{6}{|c|}{ Employment status } \\
\hline Employed & $51(49 \%)$ & $140(54 \%)$ & 0.83 & $0.52-1.30$ & 0.407 \\
\hline Unemployed & $53(51 \%)$ & $120(46 \%)$ & & & \\
\hline \multicolumn{6}{|l|}{ Age (y) } \\
\hline$<40$ & $61(59 \%)$ & $133(51 \%)$ & 1.36 & $0.86-2.15$ & 0.195 \\
\hline$\geq 40$ & $43(41 \%)$ & $127(49 \%)$ & & & \\
\hline
\end{tabular}

$P$ value is used for chi-square test.

this vaccine, and thus, some newborns did not receive the birth dose, although universal hepatitis B immunization at birth is a current recommendation. The authors of this study recommend frequent community health education talks be held on the prevention of vertical and horizontal transmission of HBV and HCV through healthy sexual behavior and appropriate vaccination.

Findings from the current study should be interpreted within the context of its limitations. Rapid diagnostic tests were used which, when compared to enzyme immunoassays, have been shown to have a poor sensitivity $(64.5 \%$ vs. $100 \%)$ and specificity $(94.5 \%$ vs. $98.3 \%))^{33}$ Hence, the true prevalence of HBsAg and anti-HCV may have been underestimated in this study. However, rapid diagnostic tests remain valid for a cost-effective purpose in targeting a large population during a screening campaign, particularly in such a resource-challenged setting. Furthermore, limitations pertaining to the low number of participants in the younger age group will lead to the underestimation of true prevalence, as there are studies which suggest increased prevalence in children. Also, as the study population was drawn from a single district hospital, the findings may not be generalizable to the whole population.

In conclusion, this study highlights the burden of hepatitis $\mathrm{B}$ and $\mathrm{C}$ infections as major public health problems in the Mokolo health district. Prevalence rates of 28.6\% for HBV and 2.2\% for HCV infections were observed in an apparently healthy population that was completely unaware of its infection status. None of the variables assessed was found to be associated with a positive HBV status. Hence, there is an urgent need to revamp the current health policies in this rural health district through regular screening to improve disease surveillance and follow-up of $\mathrm{HBV}$ - or HCV-positive patients. Moreover, there is a need for community health education on various preventive measures for HBV and HCV infections. Further studies conducted in similar rural settings with larger sample sizes and more robust methods to identify risk factor for $\mathrm{HBsAg}$ and anti-HCV are warranted. Failure to timely detect $\mathrm{HBsAg}$ and anti-HCV in asymptomatic individuals will perpetuate the transmission of these infections, with a consequential delay in the achievement of the sustainable development goal: reduce new viral hepatitis infections by $90 \%$ and mortality by $65 \%$ by the year 2030 .

\section{Authors' Contributions}

ARN, JNT, CD and MNT: study conception and design, data collection and analysis, interpretation of results, manuscript writing and critical revision. FLT, RT and VA: critical revision of the manuscript. All the authors read and approved the final version of the manuscript.

\section{Conflict of Interest Disclosures}

The authors declare that they have no conflicts of interest.

\section{Ethical Approval}

Ethical approval was obtained from the Institutional Review Board of the Faculty of Medicine and Biomedical Sciences of the University of Yaounde I. Written informed consent was obtained from all participants prior to enrollment. All study procedures involved minimum risk to participants. Rapid diagnostic tests done for hepatitis $\mathrm{B}$ and $\mathrm{C}$ were free of charge for participants. Participants' identifications were encoded in the collection of blood samples, and sealed test results were returned to each participant after s/ he was counselled on means of prevention and treatment of hepatitis B and C infections. Participants who tested positive for either or both hepatitis $\mathrm{B}$ and $\mathrm{C}$ infections were taken care of by the viral hepatitis treatment center of Mokolo District Hospital. 


\section{Research Highlights}

\section{What Is Already Known?}

Cameroon is a highly endemic country for viral hepatitis with prevalence rates of $11.2 \%$ and $6.5 \%$ for hepatitis B Virus (HBV) and hepatitis C Virus (HCV) infections, respectively. There is little data on interventions like screening campaigns to estimate $\mathrm{HBV}$ and $\mathrm{HCV}$ seroprevalences in rural settings in Cameroon. No study to date has assessed the seroprevalence of $\mathrm{HCV}$ in the farnorth region of Cameroon.

\section{What This Study Adds?}

The current study highlights the urgent need for community health education activities on preventive measures for HBV and HCV infections, regular screening for disease surveillance, and close follow-up of disease progression in asymptomatic individuals.

\section{Acknowledgments}

We would like to acknowledge the study participants for their commitment. The authors equally thank Dr. Tambosho Afizu Chrakoh and Bissemou Jean Jacques, administrative authorities of the Mokolo's Health District.

\section{References}

1. Lemoine $M$, Eholie $S$, Lacombe $K$. Reducing the neglected burden of viral hepatitis in Africa: strategies for a global approach. J Hepatol. 2015;62(2):469-476. doi:10.1016/j. jhep.2014.10.008.

2. World Health Organization. Global hepatitis report, 2017. Geneva: World Health Organization; 2017.

3. Breakwell L, Tevi-Benissan C, Childs L, Mihigo R, Tohme R. The status of hepatitis B control in the African region. Pan Afr Med J. 2017;27(Suppl 3):17. doi:10.11604/pamj. supp.2017.27.3.11981.

4. Tran TT. Management of hepatitis B in pregnancy: weighing the options. Cleve Clin J Med. 2009;76 Suppl 3:S25-29. doi:10.3949/ccjm.76.s3.06.

5. Dwivedi M, Misra SP, Misra V, et al. Seroprevalence of hepatitis $B$ infection during pregnancy and risk of perinatal transmission. Indian J Gastroenterol. 2011;30(2):66-71. doi:10.1007/ s12664-011-0083-y.

6. Fomulu NJ, Morfaw FL, Torimiro JN, Nana P, Koh MV, William T. Prevalence, correlates and pattern of Hepatitis $\mathrm{B}$ among antenatal clinic attenders in Yaounde-Cameroon: is perinatal transmission of HBV neglected in Cameroon? BMC Pregnancy Childbirth. 2013;13:158. doi:10.1186/1471-2393-13-158.

7. Cisneros-Castolo M, Hernandez-Ruiz L, Ibarra-Robles IE, Fernandez-Garate RH, Escobedo-De La Pena J. Prevalence of hepatitis $B$ virus infection and related risk factors in a rural community of Mexico. Am J Trop Med Hyg. 2001;65(6):759763. doi:10.4269/ajtmh.2001.65.759.

8. Rabiu KA, Akinola OI, Adewunmi AA, Omololu OM, Ojo TO. Risk factors for hepatitis $B$ virus infection among pregnant women in Lagos, Nigeria. Acta Obstet Gynecol Scand. 2010;89(8):1024-1028. doi:10.3109/00016349.2010.482580

9. Obi SN, Onah HE, Ezugwu FO. Risk factors for hepatitis $\mathrm{B}$ infection during pregnancy in a Nigerian obstetric population. J Obstet Gynaecol. 2006;26(8):770-772. doi:10.1080/01443610600963986.
10. Barth RE, Huijgen Q, Taljaard J, Hoepelman AI. Hepatitis $\mathrm{B} / \mathrm{C}$ and HIV in sub-Saharan Africa: an association between highly prevalent infectious diseases. A systematic review and meta-analysis. Int J Infect Dis. 2010;14(12):e1024-1031. doi:10.1016/j.ijid.2010.06.013.

11. European Liver Patients Association (ELPA). Report on hepatitis patient self-help in Europe. http://www.hepbcppa.org/wpcontent/uploads/2011/11/Report-on-Patient-Self-Help.pdf. Accessed May 16, 2017.

12. Institute of Medicine Committee on the $\mathrm{P}$, Control of Viral Hepatitis I. In: Colvin HM, Mitchell AE. Hepatitis and liver cancer: a national strategy for prevention and control of hepatitis B and C. Washington (DC): National Academies Press; 2010.

13. Ott JJ, Stevens GA, Groeger J, Wiersma ST. Global epidemiology of hepatitis B virus infection: new estimates of age-specific HBsAg seroprevalence and endemicity. Vaccine. 2012;30(12):2212-2219. doi:10.1016/j.vaccine.2011.12.116.

14. Madhava V, Burgess C, Drucker E. Epidemiology of chronic hepatitis $C$ virus infection in sub-Saharan Africa. Lancet Infect Dis. 2002;2(5):293-302. doi:10.1016/S1473-3099(02)002645 .

15. World Health Organization. Guidelines for the prevention, care and treatment of persons with chronic hepatitis B infection. Geneva; WHO Press; 2015.

16. World Health Organization. Guidelines on hepatitis B and C testing. Geneva: World Health Organization; 2017.

17. Bigna JJ, Amougou MA, Asangbeh SL, et al. Seroprevalence of hepatitis B virus infection in Cameroon: a systematic review and meta-analysis. BMJ Open. 2017;7(6):e015298. doi:10.1136/bmjopen-2016-015298.

18. Bigna JJ, Amougou MA, Asangbeh SL, Kenne AM, Nansseu JR. Seroprevalence of hepatitis $C$ virus infection in Cameroon: a systematic review and meta-analysis. BMJ Open. 2017;7(8):e015748. doi:10.1136/bmjopen-2016-015748.

19. World Health Organization. Expanded Programme on Immunization: Report of the 14th global Advisory Group. Geneva: World Health Organization; 1991

20. Rey-Cuille MA, Njouom R, Bekondi C, et al. Hepatitis B virus exposure during childhood in Cameroon, Central African Republic and Senegal after the integration of $\mathrm{HBV}$ vaccine in the expanded program on immunization. Pediatr Infect Dis J. 2013;32(10):1110-1115. doi:10.1097/ INF.0b013e31829be401.

21. Stockdale AJ, Geretti AM. Chronic hepatitis B infection in subSaharan Africa: a grave challenge and a great hope. Trans R Soc Trop Med Hyg. 2015;109(7):421-422. doi:10.1093/trstmh/ trv044.

22. Annuaire Médical du Cameroun - District Sanitaire Mokolo. Available from: http://annuaire-medical.cm/ministere-santepublique/districts-sanitaires/districts-sanitaires-de-I-extremenord/152-district-sanitaire-mokolo\#. Accessed May 16, 2017.

23. World Health Organization. Relevé épidémiologique hebdomadaire. Wkly Epidemiol Rec. 2009;84(40):405-420.

24. Tchango GAN. L'accouchement à domicile au Cameroun. Disparités spatiales et essai d'explication. Proceeding of the 7th African Conference on Population: Johannesburg; 2015. http://uaps2015.princeton.edu/uploads/150217.

25. Noah DN, Andoulo FA, Essoh BVM, Ayissi GN, Bagnaka SA, Biwole Sida M. Prevalence of HBs Antigen, and HCV and HIV Antibodies in a Young Male Population in Cameroon. Open J Gastroenterol. 2015;5(12):185-190. doi:10.4236/ ojgas.2015.512028.

26. Foupouapouognigni $\mathrm{Y}, \mathrm{Mba} \mathrm{SA}$, Betsem a Betsem E, et al. Hepatitis $B$ and $C$ virus infections in the three Pygmy groups in Cameroon. J Clin Microbiol. 2011;49(2):737-740. doi:10.1128/ jcm.01475-10. 
27. Mbopi-Keou FX, Nkala IV, Kalla GC, et al. [Prevalence and factors associated with HIV and viral hepatitis B and C in the city of Bafoussam in Cameroon]. Pan Afr Med J. 2015;20:156. doi:10.11604/pamj.2015.20.156.4571.

28. Noubiap JJ, Joko WY, Nansseu JR, Tene UG, Siaka C. Seroepidemiology of human immunodeficiency virus, hepatitis B and $C$ viruses, and syphilis infections among first-time blood donors in Edea, Cameroon. Int J Infect Dis. 2013;17(10):e832837. doi:10.1016/j.ijid.2012.12.007.

29. Essome MC, Nsawir BJ, Nana RD, Molu P, Mohamadou M. [Sero-epidemiological study of three sexually transmitted infections: Chlamydia Trachomatis, Hepatitis B, Syphilis. A case study conducted at the Nkoldongo District Hospital in Yaounde]. Pan Afr Med J. 2016;25:244. doi:10.11604/ pamj.2016.25.244.11107.

30. Fouelifack Ymele F, Keugoung B, Fouedjio JH, Kouam N,
Mendibi S, Dongtsa Mabou J. High Rates of Hepatitis B and $\mathrm{C}$ and HIV Infections among Blood Donors in Cameroon: A Proposed Blood Screening Algorithm for Blood Donors in Resource-Limited Settings. J Blood Transfus. 2012;2012:458372. doi:10.1155/2012/458372.

31. Frambo AA, Atashili J, Fon PN, Ndumbe PM. Prevalence of $\mathrm{HBsAg}$ and knowledge about hepatitis B in pregnancy in the Buea Health District, Cameroon: a cross-sectional study. BMC Res Notes. 2014;7:394. doi:10.1186/1756-0500-7-394.

32. Andre FE. Overview of a 5-year clinical experience with a yeastderived hepatitis B vaccine. Vaccine. 1990;8 Suppl:S74-78; discussion S79-80. doi:10.1016/0264-410X(90)90222-8.

33. Laperche S, Boukatou G, Kouegnigan L, et al. Transfusion safety on the African continent: an international quality control of virus testing in blood banks. Transfusion. 2009;49(8):16001608. doi:10.1111/j.1537-2995.2009.02239.x. 